\title{
2. ADDRESSING THE SPATIAL TO CATALYSE SOCIO-PEDAGOGICAL REFORM IN MIDDLE YEARS EDUCATION
}

\section{INTRODUCTION}

For many years in Australia, academics and state government departments have promoted learner-centred and constructivist pedagogies in the middle years of schooling (Years 5-9) (Barratt, 1998; Beare, 2000; Carrington, 2006; DEECD, 2010; DEET, 2002; Hill \& Russell, 1999). However, such approaches have still not been widely adopted (Black, 2009; Cartmel, 2013; Pendergast, 2006; Pendergast \& Bahr, 2005).

A number of factors have hampered pedagogical reform. These have included: staff being unable or unwilling to participate in ongoing professional development; changes in leadership resulting in loss of a vision and/or financial commitment; lack of continuity in teacher cohorts; and failure to establish protocols to determine the efficacy of the reform process (Pendergast, 2006). Additionally, a 'deep spatial silence' - i.e., limited recognition about the power of space and the influence that it has over school organizational structures and learning - may have restricted the reform agenda (Fisher, 2002).

McGregor (2004b) concluded that the traditional classrooms, conceived during the Industrial Revolution and designed for students to passively receive information, have restricted school-based education to a narrow range of learning modalities and experiences. She and other academics have expressed concern about the limitations of educating today's students in such environments (e.g., Fisher, 2002; McGregor, 2004a, 2004b, 2004c; Upitis, 2004).

This concern appears to be warranted when the pedagogical intention of middle years education is to involve students in activities that involve higher order thinking (Bloom et al., 1956), experiential learning (Dewey, 1966), critical pedagogy (Friere, 1970), communication and collaboration (Vygotsky, 1996) and learning across Multiple Intelligences (Gardner, 1993, 1999).

A PhD project undertaken as part of an Australian Research Council Linkage project entitled Smart Green Schools and conducted in Melbourne, Australia investigated how changes to the physical environment might influence a) the fundamental conditions of teaching and learning for students and teachers (Elmore, 
1996), and b) the ability of school communities to engage in holistic educational reform.

As depicted in Figure 1 (below), the findings concentrated on the relationships between innovative middle years' learning environments, constructivist pedagogies and student engagement. For the purposes of the study, learning environments were defined as built environments designed as places for learning, inclusive of building structures, furniture, fixtures, technologies and resource objects.

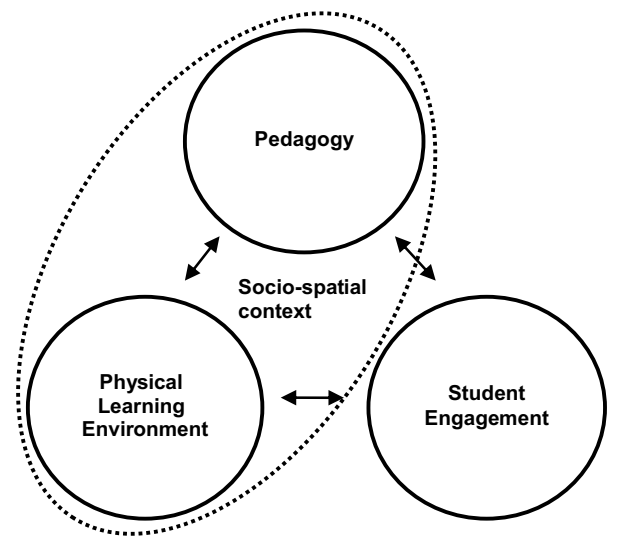

Figure 1. The study's field of inquiry: The relationships between physical learning environments, pedagogies and student engagement

\section{BACKGROUND}

In keeping with the focus of the study, the review of selected background literature that follows explores; calls for education reform; the construct of student engagement and its importance in middle years' education; recent changes to the physical learning environments in Australian schools; and the influence of the physical environment on students' educational experiences. At the intersections of these bodies of literature, gaps in the literature are identified.

\section{Calls for Pedagogical Reform vs. The Inertia of Resident School Cultures}

A new backdrop for middle years educational reform came into existence during the early 2000s - characterised by social, economic, political and cultural shifts and, perhaps most importantly, the development of new forms of information access and methods of communication enabled by digital technologies (Carrington, 2006). The types of reforms proposed at this time included those outlined by the Middle Years Research and Development (MYRAD) Project (DEET, 2002, p. web). 
This report recommended:

- Strengthening teacher-student relationships

- Involving students in decision-making about content, process and assessment

- Presenting authentic tasks that require complex thought and allowing time for exploration

- Inclusion of processes involving co-operation, communication, negotiation and social competencies generally

- Providing for individual differences in interest, achievement and learning styles.

However, it is generally agreed that reform initiatives in the middle years' have not been widely adopted (Black, 2009; Cartmel, 2013; Pendergast, 2006; Pendergast \& Bahr, 2005). Indeed, the reform agenda appears to have suffered from what Elmore described as the inertia of resident school cultures that lead school communities to powerfully resist change (Fullan, Hill \& Crevola, 2007).

\section{Student Engagement: Sub-Types and Influence}

The importance of engaging middle years' students in learning and with school has been well documented. Researchers have identified that students in the middle years' have become increasingly alienated and disengaged from school (DEET, 1999) and have identified academic stagnation as detrimental (Carrington, 2006; Hill \& Russell, 1999). Notably, the Melbourne Declaration on Educational Goals for Young Australians (MCEETYA, 2008, p. 12) concluded that, "focusing on student engagement and converting this into learning can have a significant impact on student outcomes".

Following a review of 160 studies on student engagement, Fredricks, Blumenfeld, and Paris (2004) identified three engagement subtypes. These are paraphrased below:

a. Behavioural engagement, which draws on the idea of participation and includes involvement in academic and social or extracurricular activities.

b. Emotional (or affective) engagement, which encompasses positive and negative reactions to teachers, classmates, academics, and school and is presumed to create ties to an institution and influence willingness to do the work.

c. Cognitive engagement, draws on the idea of investment (in learning) and incorporates willingness to exert the effort necessary to comprehend complex ideas and master skills.

Disengagement is believed to lead to detrimental outcomes for individuals and associated problems for the wider community. For individuals, the consequences of disengagement included a greater likelihood of leaving school early with inadequate qualifications (Kortering \& Braziel, 2008; OECD, 2000), fewer opportunities to participate in further education (OECD, 2000), and difficulties finding stable employment (Kortering \& Braziel, 2008). 
In 2002, Fisher suggested that education reform agendas have been restricted by limited recognition of the influence that space has over school organizational structures and learning. However, in recent years learning environments in schools in Australia and across much of the western world have been undergoing a process of transformation (OECD, 2009). Through this process the spaces in which students attend school are being rethought and redesigned.

In Australia, the transformation of school infrastructure was aided by a flurry of government funding schemes, the most prominent being the Federal Government's Building the Education Revolution (BER). From early 2009, the BER program distributed $\$ 16.2$ billion to fund 24,382 building and infrastructure projects in 9,526 schools nationwide (DEEWR, 2010).

This nation building economic stimulus package was initiated in the wake of the 2008 global financial crisis. With investment on this scale, and a loosening of the school infrastructure design guidelines in some Australian states, most notably in Victoria and Western Australia, innovatively designed new school buildings literally 'popped up' across the nation between 2009 and 2011.

\section{The Influence of the Physical Environment on Students' Educational Experience}

Some highlights of the limited body of research into the relationships between learning and space are outlined below.

Based on studies of human-environment interaction in schools, Weinstein (1981) recommended that the physical environments in schools should be considered to be as important as the curriculum. She proposed that physical environments could have an impact on learning through the moderation of social, psychological and instructional variables.

She suggested that the physical spaces in schools could facilitate or inhibit learning through both 'direct effects', such as noise or crowding, and through 'symbolic effects', such as when poor conditions communicate to students a lack of respect for them on the part of the school they attend. Weinstein concluded that the physical aspects of learning should be carefully planned to match teaching objectives and the learning needs of students.

As a human geographer, Fielding (2000) described unequal institutional power relations as having moulded the behaviour of students for many years. He described the degree to which students were active participants in the use of space as being largely dependent upon the structuring of the teaching, learning and management within a school.

He identified school settings in which the 'geographic moral code' was negotiated by students and teachers as positively fostering collaborative learning practices, greater fluidity of movement around the classroom, a greater amount of on-task talk within groups and little pointing, leaning over or shouting. On the other hand, 
he equated authoritarian derived pedagogy with a 'much smaller classroom', even though the physical space remained the same. With this reduction in classroom 'space', he suggested that students' geographic experiences were restricted.

Through an ethnographic study of schools in the Los Angeles area, Monahan (2002, 2005) developed the concept of 'built pedagogy': a valuable theoretical lens through which to interrogate the influence of space on educational practice. He defined built pedagogy as "the architectural embodiments of educational philosophies" (Monahan, 2002, p. web) and suggested that school spaces informed students and teachers about how they should behave by providing them with a 'script' to follow.

Furthermore, Monahan (2005) contended that built pedagogies operated along a continuum between discipline and autonomy. At one end, he suggested that space may restrict learning opportunities by not allowing for certain movements, flows or activities (discipline), while at the other end, learning environments may enable individuals to interpret space and use it as they see fit to meet their particular needs (autonomy).

\section{Gaps in the Literature at the Intersection of Space, Pedagogy and Student Engagement}

A broad review of the literature indicates that research into the influence of the physical environment on both pedagogic practice and student engagement is limited. In 2004, McGregor (2004c) suggested that the significance of space had only recently become acknowledged in education and claimed that only a few people within the education community were engaged in discourse about the impact of physical space on learning. Within the context of middle years' reform, the literature revealed only fleeting mentions of school building design or physical learning environments (e.g., Beare, 2000; Smyth, McInerney, \& Hattam, 2003; Janowska \& Atlay, 2008).

What influence innovatively designed learning environments, characterised by their interconnected spaces and high levels of resourcing, may have had on teaching and learning and the ability of school communities to engage in holistic educational reform has become a major issue in Australia. Although there was a global movement towards creating resource-rich buildings that are intended to support contemporary approaches to teaching and learning (Burke \& Grosvenor, 2008; Dudek, 2008), little research at the time of the study had focussed on the effectiveness of these facilities in supporting constructivist pedagogies and student engagement - especially in the middle years.

Informed by research into middle years' education and student engagement that emerged from the late 1980s, the study described here sought to investigate the triadic relationships between innovatively designed learning environments, pedagogies and student engagement in the pursuit of new knowledge about how physical learning environments might be better designed and used to support the constructivist pedagogies professed by middle years' researchers to improve student engagement (Barratt, 1998; Carrington, 2006; DEET, 2002; Hill \& Russell, 1999; Pendergast, 2006). By examining middle years' education through a spatial/geographical lens, it was hoped that new dimensions could be added to the discourse surrounding middle 
years' education and that the study's findings could aid the ongoing nationwide project of middle years' reform.

\section{RESEARCH DESIGN}

The key research question asked in the study was:

How can middle years' learning environments be designed and used to support contemporary constructivist pedagogies and improve student engagement?

To address this question, theoretical perspectives from the disciplines of education, architecture and human geography were married to investigate how spatial design might influence pedagogies and student engagement. Due to the breadth of the subject matter under investigation, an interdisciplinary perspective was considered essential. As different epistemologies tend to be favoured by different disciplines, an interdisciplinary approach was chosen to facilitate the creation of new knowledge regarding the socio-spatial and geo-pedagogical relationships that were central to the research question. Figure 2 (below) summarises the research foci of the study.

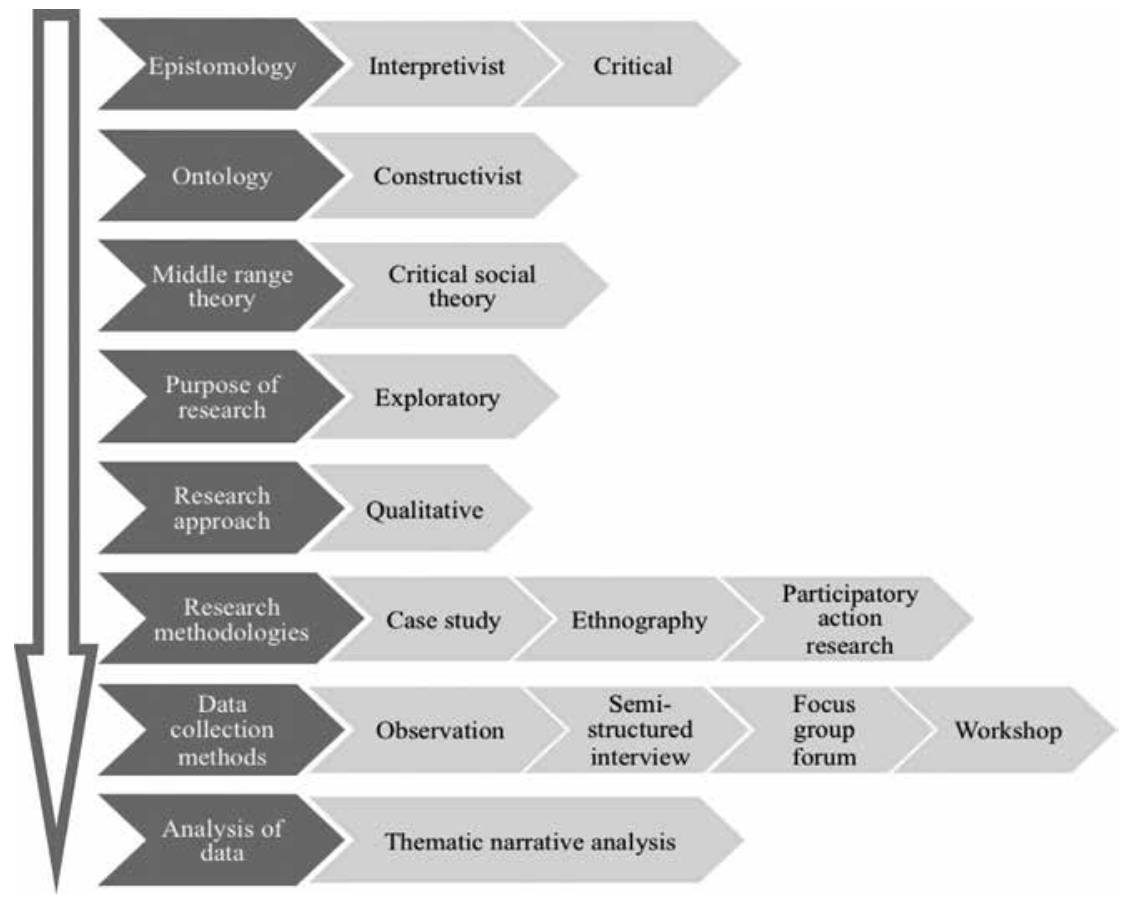

Figure 2. Design of the study 
In keeping with this framework, the study investigated the architectural response to a shift in educational practice that embraced learner-centered education models in three Melbourne-based schools. A critical analysis of middle years' learning environments was developed using multiple case study (Bryman, 2004), ethnographic (Bryman, 2004; Hammersley, 1999) and participatory action research methodologies (Cohen, Manion, \& Morrison, 2007; Mattsson \& Kemmis, 2007). The multiple case study approach enabled the research question to be investigated though the perspectives of the people directly involved in creating and using new learning environments. The field based research was conducted in schools where middle years' learning environments had been purpose built to support constructivist pedagogies.

Data were collected between September 2008 and September 2010 using a variety of qualitative methods including observation of teaching and learning - in some instances before and after the provision of the new spaces; semi-structured interviews with school leaders, teachers and students; focus groups with teachers; and workshops with school leaders, teachers and architects. Table 1 (below) outlines the dates of the significant data collection events that occurred throughout the course of the study. The principal reason(s) for each site/school visit are indicated.

The data collected were analysed using a process of thematic narrative analysis adapted from Riessman (2008). Using this technique, the data from individual cases (observational notes, interview transcripts, and summary notes from focus groups and workshops) was not fractured or segmented into thematic categories for cross analysis; instead, individual cases were maintained intact for coding. By preserving the data within each case in long chronological sequences, the finer details of the stories embedded in the data were able to be interpreted within historical contexts, with attention paid to both micro and macro contexts.

The identification of micro contexts revealed isolated issues and events that shaped the social settings in the case study schools, while an exploration of macro contexts revealed some of the forces acting on the settings' social structures - such as power relations, hidden inequalities, hidden dependencies and historical contingencies. Through the interpretation of individual cases, understandings of the socio-spatial settings and socio-pedagogical cultures of practice within the case study schools were formed.

\section{Theoretical Frameworks for Analysis and Discussion}

A number of analytical frameworks were used to explore the learning/space nexus. In keeping with the critical epistemological position that informed the study, the following domains/disciplines provided lenses through which to analyse and interpret the field data: critical pedagogy; critical theory of space; critical human geography: behaviour settings theory; complexity theory, and complex adaptive systems theory. 


\begin{tabular}{|c|c|c|}
\hline School A & School B & School C \\
\hline$\underline{2008}$ & $\underline{2008}$ & $\underline{2008}$ \\
\hline Sept 2-Observation & Sept 8 - Parent information session & Oct $29-$ Meeting with school leaders \\
\hline Sept $10-$ Meeting with school leaders & Nov 11 - Meeting with school leaders & Dec 1 - Forum/workshop to review \\
\hline $\begin{array}{l}\text { Nov } 7 \text {-Interviews with school leaders } \\
\text { and teachers }\end{array}$ & $\begin{array}{l}\text { Nov } 26 \text { - Staff professional development } \\
\text { day }\end{array}$ & current setting in the Hub \\
\hline Dec 5 -Interviews with school leaders & & $\underline{2009}$ \\
\hline and teachers & $\underline{2009}$ & Feb 11-Meeting with school leaders \\
\hline Dec 11-Observation & 27 Jan - Meeting with school leaders and & Feb 26 - Interviews with school leaders \\
\hline$\underline{2009}$ & observation & and observation \\
\hline Jan 29-Meeting with school leaders & Feb 11 - Design session with students and & Mar 12 - Observation \\
\hline Feb $10-$ Meeting with all Year 7 and 8 & observation & April 30 - Observation \\
\hline teachers and planning session with select & Feb 20 - Interview with Principal & May $14-$ Review forum with teachers \\
\hline Year 7 and 8 teachers & May 11 - Meeting to discuss furniture & May 28 - Observation and review forum \\
\hline Feb 24-Planning session with select Year & selection and observation & with teachers \\
\hline 7 and 8 teachers & May $15-$ Meeting to discuss furniture & July $30-$ Meeting with school leaders \\
\hline May 8-Observation & selection & July $31-$ Meeting with students \\
\hline May 21 -Observation & May 26 - Observation and meeting to & Aug 10-Observation \\
\hline June 4-Observation & discuss furniture selection & Aug $20-$ Visioning and design workshop \\
\hline June 18-Observation & June 9 - Observation and informal & Nov 6 - Interviews with students \\
\hline July 21-22-Curriculum review and & discussion with teachers & \\
\hline development team meeting & July 6 - Informal discussion with teachers & $\underline{2010}$ \\
\hline Aug 7 -Forum with teachers and & Aug 12 - Observation and informal & May 2 - Inspection of Hub refurbishment \\
\hline observation & discussion with teachers & Sept $15-$ Review forum with teachers \\
\hline Aug 13 - Forum with teachers and & Aug 27 - Interviews with teachers & \\
\hline meeting with school leaders & Oct $16-$ Observation and informal & \\
\hline Sept 16- Interviews with school leaders & discussion with teachers & \\
\hline and teachers & Nov 10 - Learning spaces multimedia & \\
\hline Oct 29 - Interviews with teachers and & activity with students & \\
\hline students & Nov 17 - Review forum with teachers and & \\
\hline Nov 12 - Interviews with students & interviews with students & \\
\hline$\underline{2010}$ & Dec 17-Interviews with students & \\
\hline \multicolumn{3}{|l|}{ Jan 28 - Review forum with school } \\
\hline \multicolumn{3}{|l|}{ leader, teachers etc. } \\
\hline \multicolumn{3}{|l|}{ Feb 11 - Review forum school leaders } \\
\hline and teachers & & \\
\hline
\end{tabular}

The lens of critical pedagogy (Freire, 1973; Friere, 1970; Giroux, 1985) was used to examine the motivations, objectives and intentions of those who directed the spatial and pedagogical projects in the case study schools - namely the school leaders. This lens was used to examine their educational rationales for change, their educational visions for the future, and the expectations they held about the influences that innovative learning environments may have on middle years' sociospatial contexts and socio-pedagogical cultures. 
Perspectives derived from the literature on critical theory of space (Soja, 1989) and critical human geography (Fisher, 2002; Foucault, 1972; Hirst, 2005; Lees, 2001; Lefebvre, 1991) were used as an overarching perspective from which to discuss how teachers and students used and experienced space. In particular, Soja's (1989) theories about how critical spatialization may open up avenues for the (re) interpretation of social histories were used to examine the events that occurred as teachers and students made the transition into new learning environments.

Behaviour settings theory (Barker, 1968) was used to discuss the influences that 'units of the environment' had on the behaviour of teachers and students. As behaviour settings theory recognises both physical and social components of the environment, this theoretical lens matched particularly well with the focus of the study on the relationships between the physical learning environment, pedagogy and student engagement.

In order to build on the discourse that was initiated by Upitis (2004) regarding the connections between complexity theory, educational practices and school architecture, complexity theory (Heylighten, Cilliers, \& Gershenson, 2007) and complex adaptive systems theory (Law \& Urry, 2004) were used to develop understandings of the emergent behaviours that occurred in the case study schools. These conceptual tools enabled discussion of the effectiveness of the new learning environments in the case study schools and the development of ideas regarding what role architecture could play within a complex adaptive system of education.

\section{CASE STUDY SITES}

The selection of case study sites was made using a process of convenience sampling (Bryman, 2004). The three schools (given pseudonyms) were state funded public schools located in metropolitan Melbourne however they differed in a number of ways: one was a primary school, the other two were secondary schools; the schools catered for significantly different numbers of students; the communities served by the schools were stratified by socioeconomic status; the schools were geographically distributed across the metropolitan area (each was situated within a different Department of Education and Early Childhood Development regional office zone); and the designs of the new 'innovative' learning environments varied between schools.

The sites are introduced below. The information provided includes: an overview of each school; details of recent infrastructure changes; a brief description of the learning environments/settings that were studied; and a brief outline of the research process conducted.

\section{School A - Suburban HS}

Suburban HS was a large co-educational school located in outer metropolitan Melbourne. It was attended by more than 2000 students in Years 7 to 12 
(in 2009-2010) and employed 250 teachers and auxiliary staff. Many of the students were from disadvantaged socio-economic backgrounds, with a high proportion of the school's families being recent immigrants to Australia. The school was formed in 2009 following the merger of three existing schools. It was hoped this amalgamation would improve the educational outcomes for students in the area.

Fieldwork at Suburban HS was conducted mainly within one of the school's new 'school within school' buildings - facilities designed to house 300 students from Years 7-12. The focus was on the educational settings on the first floor, where three teachers, and cohorts of 50 Year 7, 50 Year 8, and 50 Year 9 students (not included in the study) were accommodated (see floor plan in Figure 3 below).

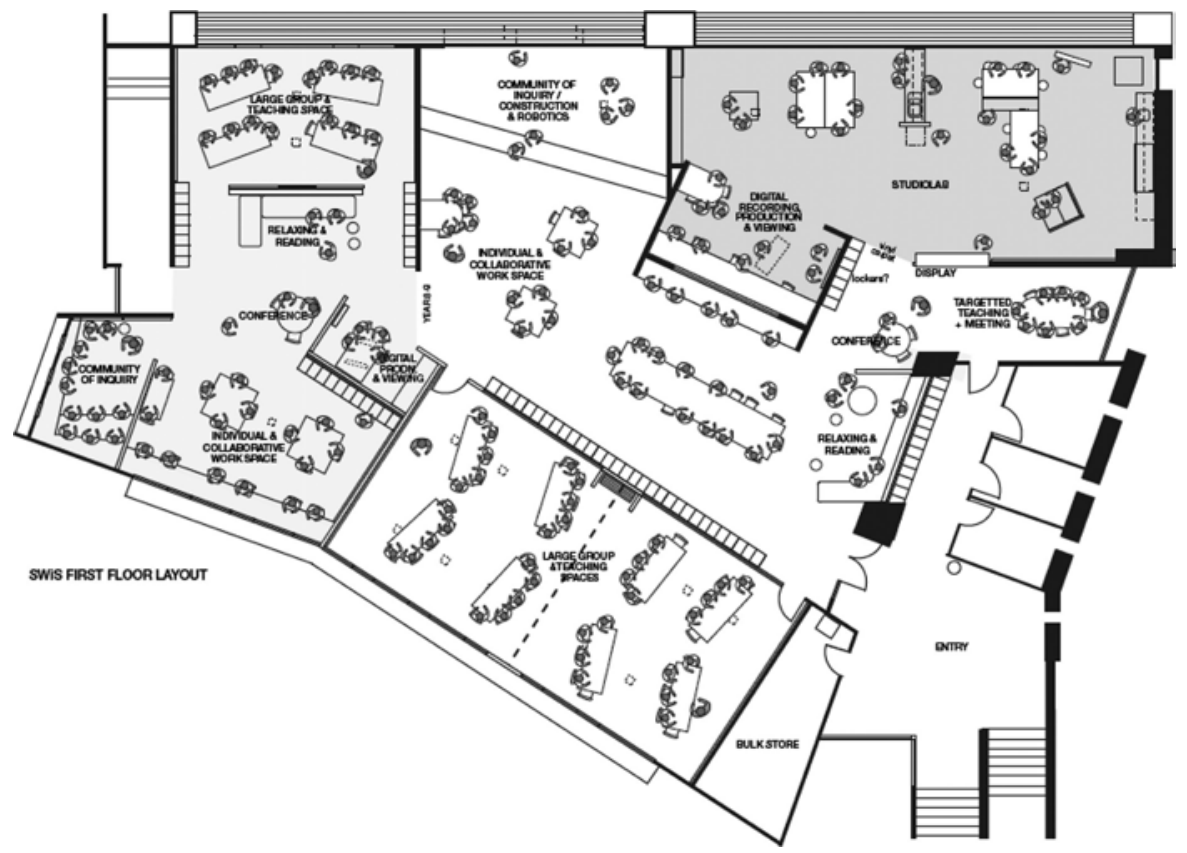

Figure 3. Suburban HS: SWiS building first floor (Image: Hayball and Mary Featherston Design)

\section{School B - Inner City PS}

Inner City PS was a small co-educational school that catered for 275 students in Prep to Year 6 (2008-2010). The school campus, located on a compact site in a privileged socio-economic area in an inner suburb of Melbourne, was first established in 1873 (now heritage listed buildings). Less than $10 \%$ of students were from homes where a language other than English was spoken (citation withheld). 
In 2008 a new Principal and Assistant Principal had inherited a building refurbishment project in its early stages. The focus of this project was on updating the Year 5/6 learning area. The incoming Principal wished to create a more engaging educational experience for the Year 5/6 students, who he viewed as highly able but insufficiently challenged. He wished to shift from an educational model that was defined by a social organisational structure of 25 students working with a single teacher, to a new model based on three teachers working collaboratively with 75 students. He viewed the building project as a significant opportunity to realise this goal. The majority of fieldwork undertaken at this site was conducted within the Year 5/6 area, as depicted in Figure 4 (below).

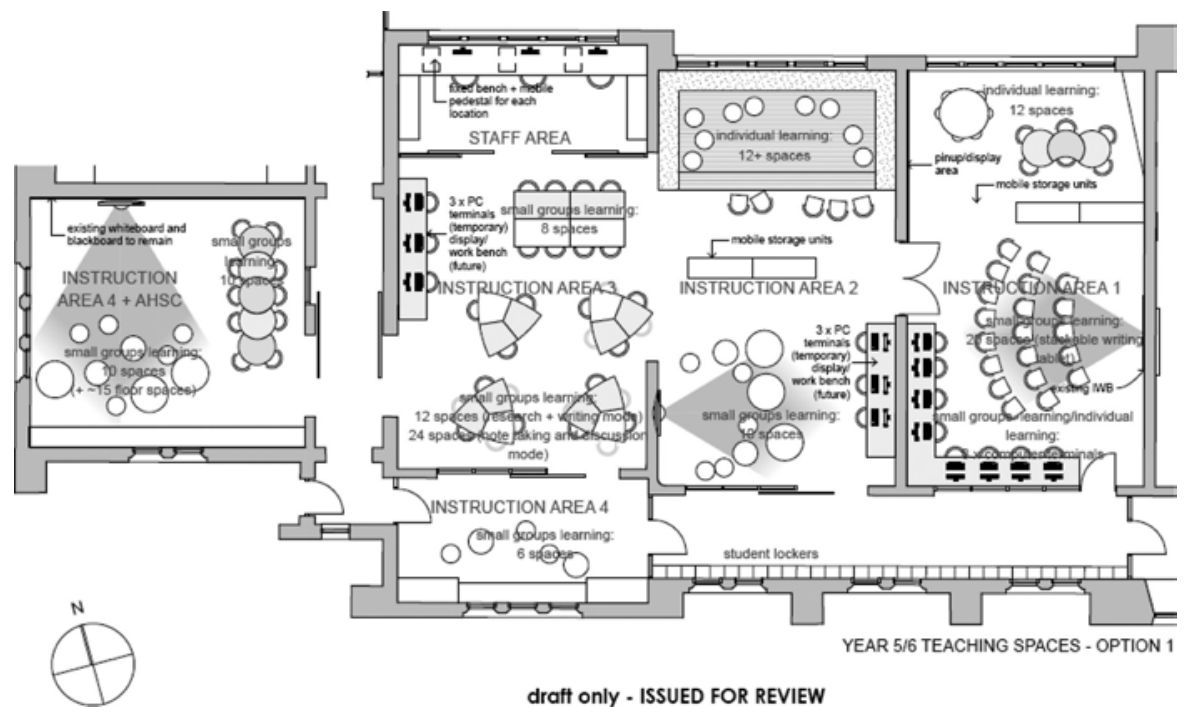

Figure 4. Inner city PS: Year 5/6 area following renovation/refurbishment in 2009 (Image: Cathi Cola architects)

\section{School C-Seaside SC}

Seaside SC was a co-educational school with a student population of more than 1400 in Years 7-12 (2008-2010). The school was located in a bayside suburb of Melbourne with a high socio-economic status. The middle years' campus (Years 7-9) was the focus of the research at this school. Significant changes were instigated at this campus in 2000, when Seaside SC merged with a school that had previously occupied the site. The merger of the two schools coincided with a $\$ 13$ million building program that brought about the demolition of the campus' existing buildings and the construction of new buildings - first occupied in 2007. 
The new buildings comprised traditional classrooms, with the exception of a large space known as the 'Hub'. This space was the focus for the fieldwork at this site. Located on the first floor of Building B (see Figures 5 and 6 below), the Hub was equivalent in size to four traditional classrooms; including what would be a central corridor. Figure 5 (below) shows the Hub in 2008 when fieldwork began. Figure 6 (also below) depicts the same space in 2010, post-refurbishment.

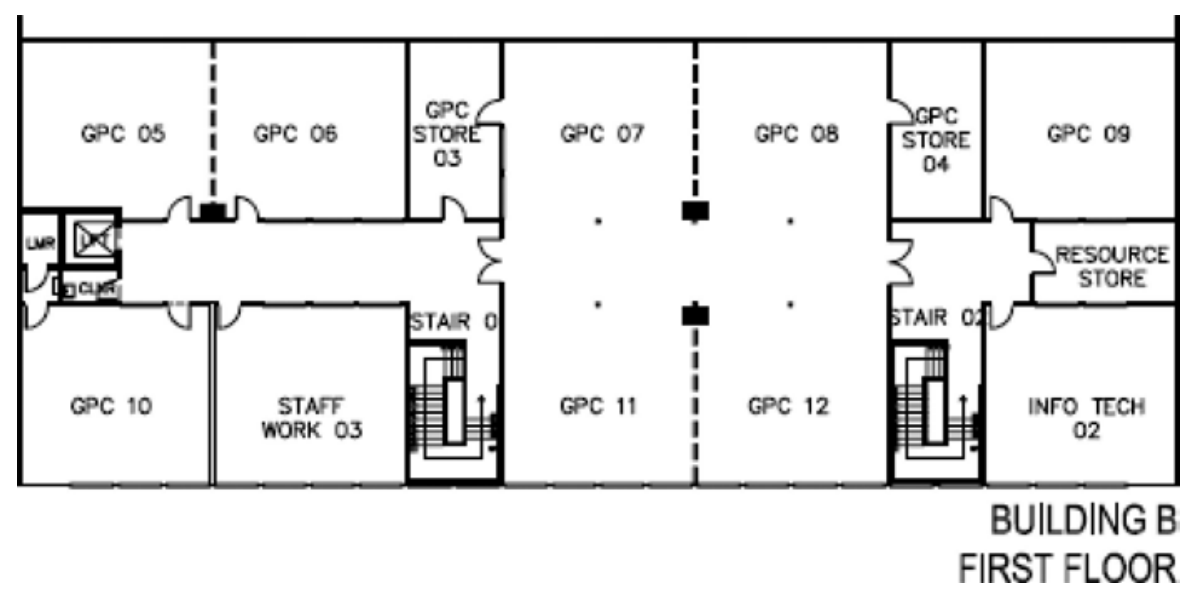

Figure 5. Seaside $S C$ : The hub $(G P C 7,8,11,12)$ prior to refurbishment (Building $B$-First floor)

\section{FINDINGS AND DISCUSSION}

The findings that emerged from the data about students' and teachers' geopedagogical experiences in the case study schools - experiences associated with learning and teaching as seen through a human geographic lens - revealed that the innovatively designed spaces in the case study schools offered both opportunities and challenges to students and teachers.

The new spaces were found to catalyse pedagogical and cultural change by challenging the prior practices of inhabitants, but did not directly shape new practices or behaviours. Indeed, pedagogical and cultural change was only achieved after overcoming early tensions and resistance to change, particularly from teachers. While some responded positively to the educational and professional opportunities offered by the new spaces, others expressed unease, apprehension and apathy regarding new learning environments and associated changes to curriculum, pedagogy and assessment practices. Shifting teachers' pedagogical approaches required more than just the 'disturbance' that new spaces caused.

The majority of teachers required professional learning support in order to adopt constructivist pedagogies and further assistance from school leaders and others, 


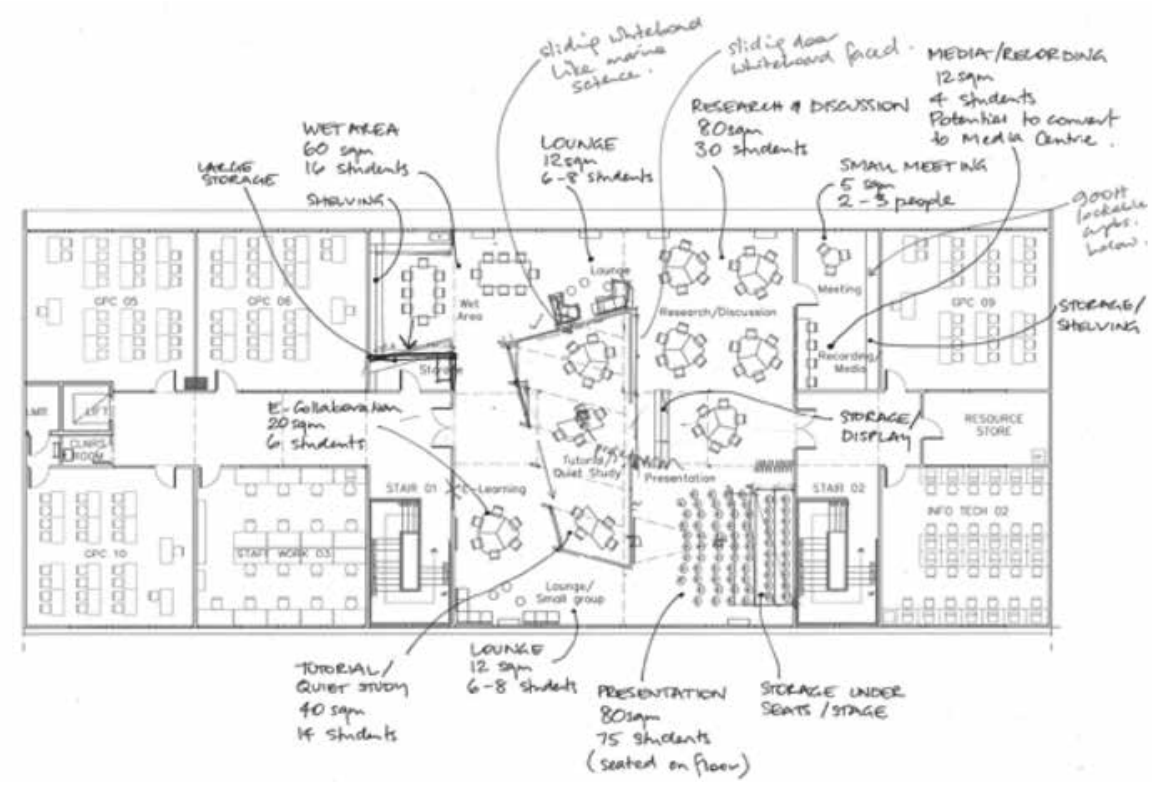

Figure 6. Seaside SC: The hub refurbishment floor plan - Annotated (Building B-First floor) (Image: Spowers architects)

including educational consultants, before they took advantage of the pedagogical opportunities afforded by the innovative learning spaces.

The key findings arising from the study associated with students' and teachers' geo-pedagogical experiences within the new learning environments of the case study schools and the influence of this on student engagement are presented and discussed below, as emerged from the thematic narrative analysis of the data (Riessman, 2008).

\section{"Where is the Front"? Teachers' Early Experiences in Innovative Learning Environments}

The geo-pedagogical experiences afforded by the new learning environments in the case study schools were vastly different from those afforded by traditional classrooms. For many teachers, the settings that confronted them were not familiar. The initial bewilderment that some teachers experienced when they first encountered the innovative spaces in their schools was highlighted in the following quote from a school leader at Suburban HS:

The kids were all standing around thinking what do we do now, and the teacher said to me, "Where is the front?", and I said, "What", and she said, "Where 
is the front of the room, where do I stand?", and I said, "Well, wherever you want to stand", and she said, "No, no, no, to teach, where do you want me to stand?"

Confronted by interconnecting spaces, collaborative table settings, soft seating areas and ubiquitous computer access to students (via laptops and fixed computers), many teachers (and students) did not recognise the behaviour settings (Barker, 1968; Gump, 1980) in the new spaces. Not only were the physical components, or milieu, different from traditional classrooms, but the social components, including the human components and the program (standing patterns of behaviour) were foreign or had not yet been established. With two or three times the numbers of students in each cohort (50 or 75 depending on the school) and the expectation that three or four teachers would teach collaboratively, the social dynamics in these new environments were fundamentally different from those that teachers were accustomed to in traditional classrooms. As a result, teachers (and students) were initially uncertain about how to behave in these new settings.

\section{Cultural Change, Collaboration and the Social Production of Innovative Learning Environments}

Observations and interviews revealed that although innovative learning environments mediated new forms of social relations, many teachers were not initially empowered when it came to appropriating or manipulating unfamiliar settings to support their pedagogical objectives. In general, teachers lacked environmental competencies (Lackney, 2008). However, as their perspectives on how learning occurred changed, they developed new practices, began to embrace the educational opportunities afforded by innovative learning environments and developed new environmental competencies that allowed them to make better use of the innovative spaces. A teacher at Inner City PS commented:

Opening the student learning space has meant that we are interacting, planning, refining, philosophising, you know ... It is constant. It is just this constant professional conversation that we are having and I think that part of the reason that we all get exhausted by the end of the week is because we are so stimulated by what we are doing. I've been teaching for over 20 years ... but I'm finding it the best teaching that I have done.

The social production of space in the case study schools was driven by discourse and collaboration. Initially, teachers worked together in teams to develop and later refine new pedagogical frameworks in response to new physical settings and the expectations of school leaders - a process enhanced by the co-location of teachers in common study areas. Subsequently, ongoing discourse and collaboration with students supported the creation of shared understandings regarding the expected norms of behaviour. With this, new geo-pedagogical practices were developed. 
Shifting the value systems through which teachers framed their professional conduct was essential for bringing about pedagogical change. Engaging teachers in discourse about contemporary educational theory, as well as allowing time for reflection, were suitable techniques for developing their understanding of constructivist pedagogies and refocussing the lenses through which they interpreted what was going on in particular learning situations. In addition, the new environmental competencies that teachers (and students) developed enhanced their ability to employ constructivist pedagogies. With opportunities for spatial and pedagogical experimentation and reflection, ineffectual pedagogies and spatial usage schemas were cast aside, while those found to be more effective were continued and refined.

Thinking collaboratively and creatively about varied pedagogical approaches was integral to teachers adopting new roles as leaders of constructivist education. As they developed new environmental and pedagogical competencies, they became better equipped to take on the task of creating dynamic behaviour settings that could support socio-pedagogical cultures that were conducive to learning.

\section{Towards Pedagogical Change}

Poor design, characterised by limited spatial differentiation and poor acoustics, hindered the uptake of constructivist pedagogies. To accommodate the 'learning hum' associated with the verbal communication required of constructivist pedagogies, the inclusion of high quality acoustic materials was critical. Poor acoustic design was found to place pressure on teachers to revert to highly structured teacher-directed pedagogies. A teacher at Inner City PS commented:

Sometimes it feels crazy, particularly in the larger space, and your teacher instincts go, "It's too loud, it's too loud. No one can work when it is like this". And sometimes that is the case, and you need to quieten them down. I'm not saying it's always great. Sometimes they are mucking around and you need to pull them back. But a lot of the time ... they are really into what they are doing and they just want to share. And it comes out in our data-huge connectedness to other students here. They really help each other and they really support each other and they look after each other.

Traditional timetabling arrangements were also found to restrict the adoption of constructivist pedagogies. Lessons of a short duration (approximately 50 minutes) were found not to be supportive of constructivist learning, while lessons of a longer duration (up to 150 minutes) were identified to better support student participation in a variety of related constructivist learning activities.

The limited proficiency of teachers with technology also reduced opportunities for students to learn via virtual/digital learning experiences, such as inquiry-based, self-directed project work. 


\section{Students’ Transition into Innovative Learning Environments}

The majority of students across the three case study sites made the transition into the innovative learning environments at their respective schools with relative ease. They enjoyed their new geographic freedom and the variety of pedagogical encounters that their new spaces enabled.

An exception to this ease of student transition was witnessed at Seaside SC before the Hub was refurbished. In its original state, this large homogeneous environment left students unsure about how they should behave or participate in learning activities. Such uncertainty placed significant pressure on teachers to try to socially produce appropriate behaviour settings for learning in an environment that provided few 'environmental cues' (Barker, 1968) to direct students' activities.

In its original incarnation, teachers described the Hub as "like a gym", and as an "open space that made the kids want to run around". Some teachers suggested that it wasn't simply the overall size of the space that made it problematic. They believed that limited access to resources and the lack of well-defined settings within the space contributed to students finding it difficult to develop an affinity for the learning environment.

Following the refurbishment of the Hub, students recognised the environmental cues associated with particular settings and generally behaved in ways that were in keeping with the settings they occupied. In this way they appropriated settings as they needed them, rearranged furniture items to meet their needs and relocated between settings to pursue different aspects of collaborative, inquiry-based projects.

Across the three sites, access to interconnected learning environments allowed students to participate in activities that may not have been supported by traditional classrooms. For example, they spread sizeable materials, such as newspapers, out on the floor, or relocated to make use of larger tables. The inclusion of readily accessible wet areas at Suburban HS and the Hub at Seaside SC also enabled students to access art and craft resources. The advantage of having access to a range of learning settings was noted by students:

Here you have 'air to breathe' ... being able to move around and do more stuff ... There are spaces for multimedia, there are open spaces for physical activity, and there are the more traditional spaces ... there is so much you can do compared with our old buildings. (Suburban HS student)

\section{Students' Geographic Freedom and Spatial Preferences}

The places students chose to locate themselves had implications for their learning in the eyes of some teachers. For example, a teacher at Inner City PS expressed concern about students' handwriting and the conceptual quality of their work when they chose to locate themselves in 'inappropriate' physical settings. To encourage the 'appropriate' use of space by students, the teachers at Inner City PS integrated discussions about the use of space into their daily practices. 
As a result of this dialogue, students tended to make better geographic choices. At Suburban HS, students were asked to plan how, when and where they would work on projects. Such facilitated metacognition regarding the use of space appeared to play an important role in supporting the development of students' environmental competencies (Lackney, 2008) and to empower them as self-directed learners. One student at Suburban HS suggested that, "Here you can learn while having the freedom to move around". While another student commented that:

It is easy for us to access things like computers, technology and making things, like for models and posters ... we can stay in one area and do one thing, while others work [elsewhere] on another thing, and we don't get mixed up. (Suburban HS student)

In addition to the learning opportunities afforded by new environments, the overall comfort that students experienced in these spaces was important to them. During interviews, students made references to features associated with thermal comfort, air quality and light levels, and described these environmental factors as influencing their like or dislike of particular environments or settings. In addition, they suggested that the materials with which they came into contact were important. Many students identified intimate settings as their favoured locations to engage in learning. This information correlated well with observations of their use of space.

\section{Spatial Ownership, Surveillance and the Development of Constructivist Pedagogies}

Spatial ownership and surveillance played key roles in supporting the development of new pedagogical cultures. The shared ownership of space supported democratisation of the learning situation and enabled students to pursue learning activities with greater self-direction. Surveillance by both teachers and students was observed to encourage social cohesion and enable teachers and students to work together collaboratively.

The release of control over students' geographic experiences followed a process in which teachers re-conceptualised how and when learning occurred. Subsequently, this led teachers to gradually adopt new pedagogies that focused more heavily on the 'processes' of learning rather than on the 'products' of learning (such as completed assessment tasks). As teachers' perceptions changed, they began to see the potential benefits that greater geographic freedom could bring to the learning situation. In particular, they recognised that allowing students to decide where, and often with whom, they engaged in learning led to students taking greater responsibility for their own learning. An Assistant Principal at Suburban HS commented:

We have had to learn to use the spaces. There has been a continuum from past pedagogy to the current pedagogical practices. As the teachers become more comfortable they allow for a greater variety of activities to occur in the spaces 
... Students are learning to use the spaces independently in ways not intended by the teachers. Students use the space in spontaneous ways that are developed from their natural ways of learning. Really good sensitivity to the concepts and theories of learning is required to understand what is going on upstairswhere the learning spaces allow for freedom and choice of environment and resources. The new learning spaces invite choice, rather than a traditional classroom that required continuous decisions to be made [by teachers] before activity was initiated.

The release of teacher control over students' geographies provided further evidence that the new architecture and the educational theory that had informed the spatial and pedagogical projects in the case study schools challenged teachers to re-evaluate their roles and their practices.

Across the case study schools, students and teachers expressed ownership over their learning environments through their movement of furniture and their appropriation of spatial settings. The degree to which school communities also shared ownership of space was a significant factor in the development of new pedagogical approaches. In situations where ownership of space was not shared, the development of new pedagogies was hindered.

Time was also found to be a factor that influenced both teachers' and students' expressions of spatial ownership. The amount of time that students and teachers spent within particular learning environments influenced their affinity for particular physical settings and their abilities to utilise these spaces effectively. At Suburban HS and Inner City PS the same student and teacher cohorts occupied the same learning environments for the majority of each school day.

This enabled them to develop good understandings of their environments and a shared sense of ownership. At Seaside SC, however, student and teacher cohorts only occupied the Hub for approximately four hours per week. This situation created limited opportunities for students and teachers to develop a shared understanding of the physical and social aspects of the Hub. This demonstrated that students and teachers required consistent access to innovative learning environments if they were to develop ownership over these spaces and become adept users of these spaces as sites for constructivist learning.

Improved social cohesion appeared to be generated when teachers and students engaged in ongoing discourse regarding the expected norms of behaviour that were associated with the use of space, and subsequently when both teachers and students engaged in acts of discipline and surveillance.

This demonstrated that 'power-knowledge' did not emanate from simple centres (the teachers in this case), but was networked throughout these social bodies via diverse relationships (Hirst, 2005). Such networking across these learning communities aided the development of new socio-pedagogical cultures that exhibited democratic qualities. In turn, this democratisation appeared to support student participation in constructivist learning activities. 
In keeping with the findings reported above, two new constructs were found at the intersection of space and learning: 'reflexive learning environments' and 'student geographical engagement'. These are introduced below.

\section{Reflexive Learning Environments}

The teaching and learning behaviours observed in the case study schools indicated that middle years' learning environments should be designed with the express intention of supporting a variety of pedagogical encounters and greater geographic freedom than is afforded in traditional classrooms. Furthermore, the findings indicated that learning environments should be characterised by a reflexive quality if they are to support the complex interactions associated with learner-centred and constructivist middle years' education models.

'Reflexivity' is different to 'flexibility' - a term that is widely used by educators and architects to describe spaces that are intended to cater to a variety of learning experiences (Woodman, 2011). As conceptualised here, reflexive spaces are physical environments that both inform pedagogical encounters and are informed by pedagogical encounters via a bi-directional relationship between the physical environment and inhabitants.

While flexible spaces suggest nothing about the role that space can play in informing teachers and students about how they might engage in particular learning activities, reflexive spaces suggest to users how they might participate in activities, while still enabling them to fine tune physical settings to meet their pedagogical needs. While the utility of flexible spaces (too often filled with homogenous mobile furniture) is largely dependent on the environmental competencies of users (Lackney, 2008), reflexive spaces encourage a range of pedagogical encounters by providing teachers and students with environmental cues that support their mastery of the use of space.

\section{Student Geographical Engagement}

The study showed that the design of the physical learning environment influenced student engagement. Indeed, high levels of engagement were supported by spaces that afforded:

- Opportunities for students to engage in a diverse range of activities/pedagogical encounters;

- Opportunities for flexible grouping arrangements that offered students regular transition between working on their own and as members of various sized groups; and

- Student access to a variety of learning resources and materials, including ICT. 
It is suggested here that 'geographical engagement' should be considered an important sub-type of the 'student engagement' construct, along with behavioural, emotional and cognitive engagement (Fredricks, Blumenfeld, \& Paris, 2004). Geographical engagement was associated with students' affinity for their surroundings, the sense of place they feel in connection with their school learning environments, and their ownership and mastery of their environment (including material and technological resources).

Observations in the case study schools revealed that geographical engagement was expressed by students in the ways they socially produced space (McGregor, 2004b) in support of their learning activities and by their ability to participate in learning activities with some autonomy. The majority of students developed reasonably high levels of geographical engagement following a short period of adjusting to new environments and social programs. For the majority of students, liberation from traditional classroom settings empowered them to take on more responsibility for their learning.

Subsequently, the relative success they experienced as self-directed learners appeared to be correlated with their levels of geographical engagement. The students who gained most from complex interactions with other people, their environment and technology were those who developed an affinity for their environment and were therefore able to make good use of the learning resources available to them. Additionally, high levels of geographical engagement were correlated with the ability of students' to show initiative and work with a high degree of independence from teachers.

\section{CONCLUSION}

The disruption caused by the creation of the new learning environments in the case study schools created opportunities for new practices and behaviours to emerge. In response to Elmore's suggestion that powerful pervading cultures in schools often act to maintain the status quo and negate systemic change (Fullan, Hill, \& Crevola, 2007), it is the contention of this author that these cultures are embodied in the built pedagogy (Monahan, 2002, 2005) of traditional classrooms and that such cultures may be altered by changing the design and subsequent socio-spatial contexts in schools. The study demonstrated that if teaching and learning conditions are to be improved, educational reform agendas should include changes to the built environment.

The study showed that carefully considered and innovatively designed learning environments could catalyse changes to socio-pedagogical cultures, support the adoption of constructivist pedagogies, and encourage higher levels of student engagement. The findings also clearly indicated that teachers require ongoing professional learning support if they are to adopt constructivist pedagogies and make the most of innovatively designed learning environments. A combination of external professional development seminars and regular internal learning opportunities 
which expose teachers to contemporary educational theory, address new spatial usage schemas and provide opportunities for reflection on past and current practices appears to be necessary.

\section{REFERENCES}

Barker, R. (1968). Ecological psychology. Stanford, CA: Stanford University Press.

Barker, R. (1976). On the nature of the environment. In H. M. Proshansky, W. H. Ittelson, \& L. G. Rivlin (Eds.), Environmental psychology: People and their physical settings. New York, NY: Holt, Rinehart and Winston.

Barker, R., \& Gump, P. V. (1964). Big school, small school: High school size and student behaviour. Stanford, CA: Stanford University Press.

Barratt, R. (1998). Point and counterpoint: The future: The shape of middle schooling in Australia. Curriculum Perspectives, 18(1), 9-13.

Beare, H. (2000). Creating the future school. London, England: Routledge Falmer.

Black, R. (2009). Because schools can't do it alone: Partnerships for the middle years. Primary and Middle Years Educator, 7(2), 16.

Bloom, B. S., Engelhart, M. D., Furst, E. J., Hill, W. H., \& Krathwohl, D. R. (1956). Taxonomy of educational objectives: Handbook 1 - Cognitive domain. New York, NY: David McKay.

Bryman, A. (2004). Social research methods (2nd ed.). Oxford, England: Oxford University Press.

Burke, C., \& Grosvenor, I. (2008). School. London, England: Reaktion Books.

Carrington, V. (2006). Rethinking middle years: Early adolescents, schooling and digital culture. Crows Nest, Australia: Allen \& Unwin.

Cartmel, T. (2013). Crafting the middle years mosaic. Primary and Middle Years Educator, 11(3), 3.

Cohen, L., Manion, L., \& Morrison, K. (2007). Research methods in education. New York, NY: Routledge.

DEECD. (2010). The principles of learning and teaching P-12 background paper (pp. 1-12). Melbourne, Australia: Department of Education and Early Childhood Development.

DEET. (1999). The middle years: A guide for strategic action in years 5-9. Victoria, Australia: Department of Education, Employment and Training.

DEET. (2002). Middle years research and development project: Executive summary. Victoria, Australia: Department of Education, Employment and Training. Retrieved from www.eduweb.vic.gov.au/ edulibrary/public/curricman/middleyear/research/MYRADExecSummary.doc

DEET. (2007). The middle years of schooling: A guide to planning teaching assessing and reporting. Northern Territory, Australia: Department of Education, Employment and Training. Retrieved from www.middleyears.nt.gov.au/middle-years/teaching_learning/docs/guide/middle_years_guide.pdf

DEEWR. (2010). Building the education revolution: National coordinator's implementation report February-September 2009. Canberra, Australia: Department of Education, Employment and Workplace Relations.

DET. (2006). Our middle years learners - Engaged, resilient, successful: An education strategy for years 5-9 in NSW 2006-2009. New South Wales, Australia: Department of Education and Training. Retrieved from www.det.nsw.edu.au/media/downloads/newsroom/yr2006/oct/middleyrs.pdf

DETA. (2003). Middle phase of learning state school action plan. Queensland, Australia: Department of Education Training and the Arts. Retrieved from http://education.qld.gov.au/etrf/pdf/midaction03.pdf

Dewey, J. (1966). Experience and education. New York, NY: Collier Books.

Dudek, M. (2008). Schools and kindergartens: A design manual. Berlin, Germany: Birhauser.

Elmore, R. F. (1996). Getting to scale with good educational practice. Harvard Educational Review, 66(1), 1-26.

Fielding, S. (2000). Walk on the left! Children's geographies and the primary school. In S. L. Holloway \& G. Valentine (Eds.), Children's geographies: Playing, living, learning. London, England: Routledge.

Fisher, K. (2002). Schools as 'prisons of learning' or, as a 'pedagogy of architectural encounters': A manifesto for a critical psychological spatiality of learning ( $\mathrm{PhD}$ Dissertation). The Flinders University of South Australia, Adelaide. 
Foucault, M. (1972). The archaeology of knowledge. London, England: Routledge.

Fredricks, J. A., Blumenfeld, P. C., \& Paris, A. H. (2004). School engagement: Potential of the concept, state of the evidence. Review of Educational Research, 74(1), 59-109. doi:10.3102/00346543074001059

Freire, P. (1970). Pedagogy of the oppressed. New York, NY: Herder and Herder.

Freire, P. (1973). Education for critical consciousness. New York, NY: Seabury Press.

Fullan, M., Hill, P., \& Crevola, C. (2007). Breakthrough. Heatherton, Australia: Hawker Brownlow Education.

Fullarton, S. (2002). Student engagement with school: Individual and school-level influences (LSAY Research Report No. 27). Camberwell, England: ACER.

Gardner, H. (1993). Multiple intelligences: The theory in practice. New York, NY: Harper Collins.

Gardner, H. (1999). Intelligence reframed: Multiple intelligences for the 21st century. New York, NY: Basic Books.

Giroux, H. A. (1985). Critical pedagogy, cultural politics and the discourse of experience. Journal of Education, 167(2), 22.

Hall, K. (2010). Loris Malaguzzi and the Reggio Emilia experience. London, England: Continuum.

Hammersley, M. (1999). Researching school experience: Ethnographic studies of teaching and learning. New York, NY: Farmer Press.

Heylighten, F., Cilliers, P., \& Gershenson, C. (2007). Complexity and philosophy. In J. Bogg \& R. Geyer (Eds.), Complexity science and society. Oxford, England: Redcliffe Publishing.

Higgins, S., Hall, E., Wall, K., Wooler, P., \& McCaughey, C. (2005). The impact of school environments: A literature review. London, England: The Design Council. Retrieved April 5, 2010, from www.design-council.org.uk

Hill, P., \& Russell, J. (1999). Systemic, whole-school reform of the middle years of schooling. Paper presented at the National Middle Years of Schooling Conference, March 1999, Centre for Applied Educational Research, University of Melbourne, Melbourne, Australia.

Hirst, P. (2005). Foucault and architecture. In P. Hirst (Ed.), Space and power: Politics, war and architecture (pp. 155-178). Cambridge, England: Polity.

Jankowska, M., \& Atley, M. (2007). Use of creative space in enhancing students' engagement. Innovations in Education and Teaching International, 45(3), 271-279.

Kortering, L., \& Braziel, P. (2008). Engaging youth in school and learning: The emerging key to school success and completion. Psychology in the Schools, 45(5), 461-465.

Lackney, J. A. (2008). Teacher environmental competence in elementary school environments. Children, Youth and Environments, 18(2), 133-159.

Law, J., \& Urry, J. (2004). Enacting the social. Economy and Society, 33(3), 390-410.

Lees, L. (2001). Towards a critical geography of architecture: The case of an ersatz colosseum. Cultural Geographies, 8(1), 51-86. doi:10.1177/096746080100800103

Lefebvre, H. (1991). The production of space. Oxford, England: Blackwell.

Mattsson, M., \& Kemmis, S. (2007). Praxis-related research: Serving two masters? Pedagogy, Culture and Society, 15(2), 185-214.

MCEETYA. (2008). Melbourne declaration on educational goals for young Australians. Melbourne, Australia: Ministerial Council on Education, Employment, Training and Youth Affairs.

McGregor, J. (2004a). Editorial. Forum, 46(1), 2-5.

McGregor, J. (2004b). Space, power and the classroom. Forum, 46(1), 13-18.

McGregor, J. (2004c). Spatiality and the place of the material in schools. Pedagogy, Culture \& Society, 12(3), 347-372.

Meyer, J. (1971). The impact of the open space school upon teacher influence and autonomy: The effects of an organizational innovation. Stanford, CA: Stanford University.

Monahan, T. (2002). Flexible space and built pedagogy: Emerging IT embodiments. Inventio, 4(1), 1-19.

Monahan, T. (2005). Globalization, technological change, and public education. New York, NY: Routledge.

OECD. (2000). Student engagement at school: A sense of belonging and participation (Results from PISA 2000). Paris, France: Author. 
OECD. (2009). Innovative learning environments: International seminar and meeting of participating systems: The ILE 'universe' - Cases to date. Utdanningsdirektoratet, Norway: Organisation for Economic Co-operation and Development. Centre for Educational Research and Innovation (CERI).

Pendergast, D. (2006). Fast-tracking middle schooling reform: A model for sustainability. Australian Journal of Middle Schooling, 6(2), 13-18.

Pendergast, D., \& Bahr, N. (2005). Teaching middle years: Rethinking curriculum, pedagogy and assessment. Crows Nest, Australia: Allen \& Unwin.

Riessman, C. R. (2008). Narrative methods for the human sciences. Thousand Oaks, CA: Sage Publications.

Russell, V. J., Ainley, M., \& Frydenberg, E. (2005). Schooling Issues Digest: Student motivation and engagement. Australia: Department of Education, Science and Training, Australian Government.

Smyth, J., McInerney, P., \& Hattam, R. (2003). Tacking school leaving at its source: A case of reform in the middle years of schooling. British journal of sociology of education, 24(2), 177-193.

Soja, E. (1989). Postmodern geographies: The reassertion of space in critical social theory. London, England: Verso.

Taylor, A. (2009). Linking architecture and education: Sustainable design for learning environments. Albuquerque, NM: University of New Mexico Press.

Upitis, R. (2004). School architecture and complexity. Complicity: An international journal of complexity and education, 1(1), 19-38.

Vygotsky, L. (1996). Thought and language. Cambridge, MA: MIT Press.

Weinstein, C. (1981). Classroom design as an external condition for learning. Educational Technology, $21,12-19$.

Woodman, K. (2011). Re-placing flexibility: How does flexibility in learning spaces affect learning? (PhD Dissertation). The University of Melbourne, Melbourne, Australia.

\section{Benjamin Cleveland \\ University of Melbourne}

